\title{
Lee, Michael Parrish, The Food Plot in the Nineteenth-Century British Novel, London: Palgrave Macmillan, 2016.
}

\author{
Recensão de Iolanda Ramos \\ CETAPS/ Universidade Nova de Lisboa
}

Esta obra teve como origem uma dissertação de doutoramento intitulada "Eating and the Novel", apresentada à McGill University de Montreal em 2010, e está publicada numa colecção da Palgrave, iniciada em 2016 e dedicada à escrita e à cultura oitocentistas ("Studies in Nineteenth-Century Writing and Culture"). Composta por seis capítulos, para além da introdução e da conclusão, a monografia de Michael Parrish Lee visa dar ênfase à relação entre a alimentação e o romance britânico do século XIX. Por conseguinte, conduz o leitor num percurso que acompanha algumas das principais obras de Jane Austen, Elizabeth Gaskell, W. M. Thackeray, Charles Dickens, George Eliot, Thomas Hardy, George Gissing, Bram Stoker e H. G. Wells, analisando o desenvolvimento dos enredos sobre alimentação na ficção vitoriana até ao período finissecular. A escolha do corpus é adequada, o aparato teórico utilizado é sólido, as notas são pertinentes, a bibliografia é vasta e o índice remissivo é de grande utilidade, numa obra que se compõe de um total de 246 páginas.

0 autor recorre a uma metodologia interdisciplinar, articulando a teoria literária oitocentista e a noção de biopolítica concebida por Foucault com base no malthusianismo, 
que por sua vez relaciona a sexualidade com a oferta e a procura de comida. Apresenta também uma abordagem inovadora, ao defender a importância do enredo em torno da alimentação (food plot) a par do enredo em torno do casamento (marriage plot). Deste modo, a obra de Lee explora o papel da alimentação na ficção britânica oitocentista e sustenta que esse enredo consolida a identidade das personagens, motiva a acção e conclui a história, quer em consonância, quer em tensão, face à convencional estrutura narrativa conducente ao casamento, numa interacção que tanto promove como reprime o desejo/apetite romântico e erótico.

Como o próprio Michael Parrish Lee enuncia na Introdução, o seu estudo parte da questão aparentemente simples de apurar qual é o papel da alimentação nos romances literários. $\mathrm{O}$ texto começa por citar E. M. Forster, que sublinha o objectivo social da comida ao reunir à mesa as personagens nas obras de ficção, sem nunca mencionarem a necessidade fisiológica da alimentação. Por esse motivo, Lee inicia a sua argumentação evocando diversas personagens e vários romances oitocentistas em que é possível identificar o modo como se pode desejar, apreciar e organizar as refeições, indo para além de uma perspectiva social e limitada no que diz respeito à materialidade da comida em termos da fome, do apetite e do prazer sensorial que lhe estão inerentes.

Com efeito, o autor considera que a análise do romance britânico oitocentista não se deve limitar à estrutura narrativa do marriage plot, no qual as personagens são motivadas por sentimentos e emoções na procura de companhia e de amor. Propõe-se assim examinar a relevância do apetite material, nomeadamente, a necessidade de comer e de alimentar o corpo tendo em vista a sobrevivência básica, como fica patente tanto na fome, nos hábitos alimentares e no prazer culinário, como na escassez e na má preparação da comida, ou nos casos extremos de canibalismo e vampirismo em que a comida e a personagem se tornam uma só. Nessa medida, o papel da alimentação nos romances literários oitocentistas não é apenas social mas também fisiológico.

Como fica patente nas designações dos seis capítulos, a obra de M. P. Lee descreve a evolução desde o quase nada expresso no enredo da alimentação, estabelecido como modelo literário nos romances de Austen em termos de oposição e de subordinação ao 
enredo central do casamento, até à centralidade do enredo da alimentação nos romances do período vitoriano tardio e do fin de siècle, graças à demonstração da animalidade humana gerada pelo darwinismo e corporizada por canibais e vampiros. Para ilustrar as dinâmicas do enredo da alimentação, Lee reinterpreta obras e autores canónicos à luz dos protagonistas das classes sociais mais elevadas, que escapam a diversas formas de apetite, de modo a salientar as personagens marginais ao enredo do casamento, tais como crianças e adultos solteiros, bem como trabalhadores, criadagem, criminosos, ciganos e animais, associadas a fome, apetite e alimentação.

Apesar da génese e do desenvolvimento dos Estudos sobre a Alimentação, abordados tanto no âmbito académico como na óptica do público em geral, o autor considera que a alimentação continua a ilustrar a dicotomia entre o mundo sensorial e o intelectual, fazendo parte de uma low culture. Deste modo, o paradigma estabelecido por Austen da subordinação do enredo da comida ao do casamento continua a ser dominante, como se verifica em filmes como Bridget Jones's Diary (2001) e Eat Pray Love (2010), perpetuando a ideia de a alimentação constituir um prémio de consolação. É certo, contudo, que o food plot pode ser reinterpretado como uma celebração transgressora e libertadora de um insaciável apetite colectivo, como sucede por exemplo na obra de Seth GrahameSmith, Pride and Prejudice and Zombies (2009, adaptada ao cinema em 2016). Recorrendo a uma perspectiva original, Lee advoga que os mortos-vivos corporizam o apetite como sendo um problema demográfico biopolítico, uma vez que são devastadores, avassaladores e infindáveis.

No seu todo, e correspondendo a uma concepção interdisciplinar da literatura e da cultura inglesa oitocentista, o estudo de Michael Parrish Lee debate questões de ordem estética, remontando à análise de Platão, retomada por Kant e Bourdieu, entre outros, sobre a hierarquização dos sentidos, que privilegia a visão e a audição em detrimento do paladar na percepção da beleza e na atribuição de valor estético. Se, por um lado, a estética iluminista denegria o apetite como demasiado próximo das necessidades primárias, por outro lado, e de acordo com a ética estabelecida pela economia política de Adam Smith e Thomas Malthus, a fome desempenhava uma função moralizadora na demografia e na 
sociedade. Com efeito, ao forçar os indigentes a trabalharem e a seguirem as leis do mercado, o ethos capitalista incentivava um espírito de autonomia e de iniciativa privada que libertava o indivíduo da pobreza e da dependência. No contexto dos chamados Hungry Forties e da Irish Famine no período vitoriano, a classe média distanciava-se, assim, dos trabalhadores para se defender de consequências sociais nefastas, ao mesmo tempo que os sectores mais humanitários dessa mesma classe social prosseguiam acções de solidariedade e de empatia para com os famintos e os mais desfavorecidos da sociedade.

Ao longo do estudo, Lee chama a atenção para os vários factores que convergem na ficção britânica do século XIX, num pano de fundo em que a industrialização, o desenvolvimento do capitalismo, a consolidação do Império e aplicação das teorias darwinistas se revelam determinantes. É de especial interesse para o leitor a relação que é apontada entre o apetite colonial do período vitoriano tardio e o fascínio (neo)gótico por fenómenos carnais como fome, hábitos predatórios, canibalismo e consumo do corpo. Ao passo que no período romântico a dieta que evitava um produto dispendioso como a carne ligava, de certo modo, os ricos aos pobres, na era vitoriana a alimentação e o food plot ganham uma nova dimensão ao se associarem ao poder das nações. A importância do consumo da carne vermelha reflecte-se, por conseguinte, na Englishness presente na noção de que a carne dava saúde, força e vigor aos trabalhadores, contribuindo para a independência e a supremacia nacionais. Na verdade, a dieta alimentar carnívora confontava-se com uma dupla interpretação do vegetarianismo, por um lado vinculado à fraqueza e por outro a um estádio mais avançado da civilização face ao canibalismo e à degeneração.

Embora The Food Plot in the Nineteenth-Century British Novel não estabeleça relações directas entre os Estudos sobre a Alimentação e os Estudos sobre a Utopia (existem apenas duas curtas referências no texto, nas páginas 86 e 205, respectivamente, atribuindo uma faceta utópica à divisão do trabalho e à vida comunitária), a análise das obras de H. G. Wells, The Time Machine (1895) e The Island of Doctor Moreau (1896) explora a substituição do enredo do casamento por narrativas imperiais predatórias, nas quais os heróis satisfazem o seu apetite pelo conhecimento. Importa ressalvar também que é 
possível acrescentar-se uma vertente distópica ao food plot, visto que as obras literárias (bem como, actualmente, os filmes, séries de televisão e videojogos) protagonizadas por criaturas permanentemente famintas e que vivem para sempre na fronteira entre a vida e a morte, como os vampiros e os zombies, apontam no sentido de um futuro aterrador em que a possibilidade de se ser considerado um alimento ou a própria vida depender de se alimentar de outros seres se torna uma realidade, num mundo em que o apetite não desaparece nunca.

Em suma, a monografia de Lee propõe que a estrutura narrativa da ficção britânica oitocentista se baseia numa forma literária dupla, na qual se encontra explícito o enredo do casamento e implícito o enredo da alimentação, sobretudo à medida que, ao longo do século XIX, os enredos do casamento se tornam menos estáveis e a alimentação ganha força material e narrativa. A investigação incide sobre a teoria do romance e a relação das formas literárias com forças históricas e culturais, não se tratando de uma obra analítica apenas sobre a comida e a alimentação, mas também sobre o apetite que desafia as convenções e as normas intelectuais.

Para além de autor de contos e de textos sobre a colaboração e a competição entre personagens literárias humanas e não-humanas (animais, plantas, objectos) na ficção oitocentista, como sucede, por exemplo, nos romances de Lewis Carroll, Michael Parrish Lee é docente na Universidade de Nottingham. A presente obra contribui de modo significativo para um melhor conhecimento da literatura e da cultura britânicas do século XIX, quer para o público em geral, quer para especialistas, promovendo o desenvolvimento tanto dos Estudos Vitorianos como dos Estudos sobre a Alimentação. 